\title{
Wave attenuation characteristics of simulated heterogeneous vegetation
}

\author{
Beena Mary John*, Kiran G. Shirlal and Subba Rao \\ Department of Applied Mechanics and Hydraulics, National Institute of Technology Karnataka, Surathkal, Mangalore 575 025, India
}

Vegetated coastal ecosystems often coexist as diverse seascapes, well connected to each other by various biological, chemical and physical processes. It is of interest to study the effect of heterogeneity in vegetation using models of different combinations of submerged, emergent and compound vegetation on wave attenuation and coastal flooding. This article showcases the results of a physical model study conducted with different types of heterogeneous vegetation models in a two-dimensional wave flume, with wave height attenuation expressed in terms of percentage reduction in wave height and the subsequent extent of inundation expressed in terms of wave run-up on the beach. The test runs were carried out with monochromatic waves of height ranging from 0.08 to $0.16 \mathrm{~m}$ in water depths of 0.40 and $0.45 \mathrm{~m}$ and wave periods of 1.4-2 sec. The experimental results revealed the significant capability of vegetation in attenuating waves to the tune of $72 \%$ to $87 \%$, and controlled flooding in terms of run-up of 0.31 to 0.76 times the wave height. However, the compound heterogeneous model proved to be the most efficient in controlling wave height and coastal flooding.

Keywords: Controlled flooding, coastal ecosystems, heterogeneous vegetation, natural hazards, wave attenuation.

THE impact of climate change in coastal areas reveals increased levels of flooding, accelerated erosion, loss of wetlands and mangroves as well as increased extent and severity of storm surges, cyclones and tsunamis ${ }^{1}$. Given the rise in human population along the coast and the increase in natural hazards owing to climate change, there has been renewed interest in sustainable coastal protection measures as an adaptation strategy for coastal zones.

The geomorphology of the coast plays a vital role in the impact of natural disasters in the area, leading to increased vulnerability of the coastal population which in turn slows down the socio-economic development in the region $^{2}$. The coast, considered as a series of interconnected and interacting systems, is not only limited to merely sediment and water movements, but also encompasses an intimate relationship of plants, animals and

\footnotetext{
*For correspondence. (e-mail: beena.marie.john@gmail.com)
}

microorganisms with their physical environment ${ }^{3}$. The abiotic coastal geomorphic process is greatly influenced by biological elements such as coastal or dune vegetation $^{4}$. Vegetated dunes help in developing the morphology of the coast. The sediment-binding rhizome and root network of coastal vegetation species such as seagrasses and mangroves aid in sedimentation ${ }^{5-8}$, which further contributes to the shaping of inter-tidal morphology ${ }^{9}$.

The tropical and subtropical coastal ecosystems, characterized by seagrasses, coral reefs and mangroves, being rich in biodiversity, are also highly productive. In addition, these marine vegetated habitats aid in mitigating the impacts of natural disasters and dissipating wave energy $^{10,11}$. The effectiveness of various coastal ecosystems on wave attenuation include studies on seagrasses, coastal kelp forests, salt marshes and mangroves ${ }^{12-29}$. It is therefore noteworthy that research on wave attenuation characteristics of individual tropical coastal ecosystems is being conducted separately in each ecotype such as mangroves, seagrasses and coral reefs. From now on, it is necessary to study these ecosystems as integrated coastal ecosystems because they are linked together ${ }^{30}$.

Coastal vegetation shows a large variability of species composition across the globe. The ability of independent natural habitats such as seagrasses, kelp forests, coral reefs, salt marshes and mangroves in protecting the coast is well-researched, whereas it is still uncertain how these independent habitats complement each other in effective coastal protection ${ }^{31}$. Since these marine ecosystems are well connected to each other by various biological, chemical and physical processes ${ }^{32}$, they often coexist as spatially and dynamically heterogenous seascapes ${ }^{33}$. Therefore, it is of interest to experimentally analyse the wave height attenuation and the subsequent extent of inundation on the beaches due to heterogeneous vegetation models of different combinations of vegetation types.

\section{Material and methods}

\section{Experimental set-up}

The experiments on simulated heterogeneous vegetation were conducted in a two-dimensional wave flume $(50 \mathrm{~m} \times 0.71 \mathrm{~m} \times 1.1 \mathrm{~m})$ in the Marine Structures Laboratory, National Institute of Technology Karnataka, 


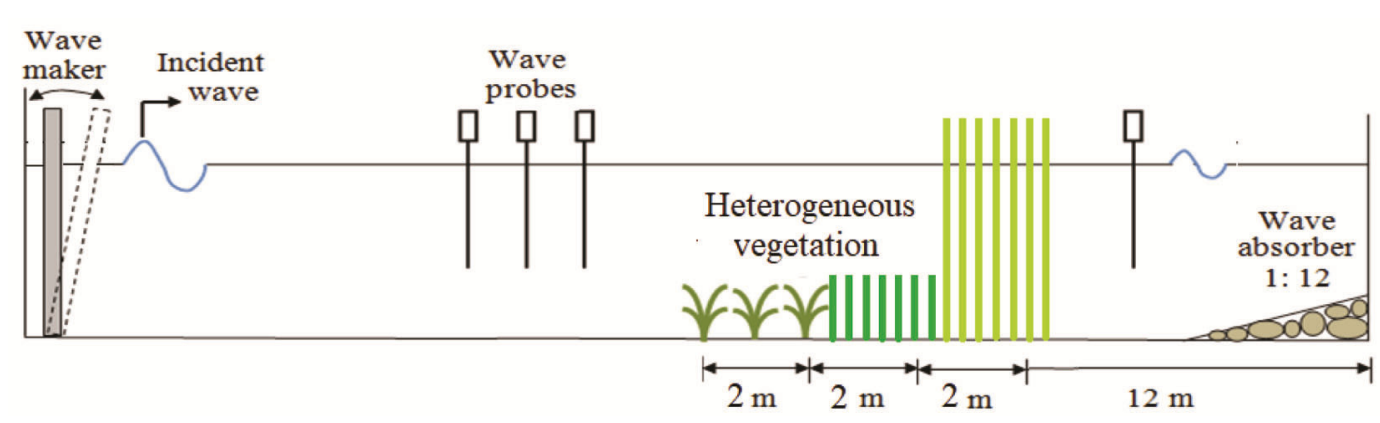

Figure 1. Schematic sketch of the experimental set-up.

Surathkal, India. Figure 1 shows a schematic sketch of the experimental set-up.

Monochromatic waves of height $0.08-0.24 \mathrm{~m}$ and period $0.8-4.0 \mathrm{sec}$ in a maximum water depth of $0.5 \mathrm{~m}$ can be generated by the flap-type wave generator in this flume facility, which has a built-in beach of slope $1: 12$ at the other end. The flap is controlled by an induction motor of $11 \mathrm{~kW}$ power at $1450 \mathrm{rpm}$. This motor is regulated by an inventor drive $(0-50 \mathrm{~Hz})$, rotating in a speed range $0-155 \mathrm{rpm}$. The capacitance-type wave probes are used for data acquisition. The spacing of probes and decomposition of incident wave characteristics from superposed waves have been accomplished using the three-probe method suggested by Isaacson ${ }^{34}$.

\section{Test models}

The effect of heterogeneity of vegetation on wave attenuation was evaluated using three different model scenarios. The first model (model I) is represented by a 'submerged heterogeneous model' of width $4 \mathrm{~m}$, which consists of a submerged seagrass model of width $2 \mathrm{~m}$, followed by submerged rigid vegetation model of width $2 \mathrm{~m}$, placed consecutively on the flume bed ${ }^{35}$. For the second model (model II), an 'emergent heterogeneous model' of width $4 \mathrm{~m}$ is considered, which is represented by a submerged rigid vegetation of width $2 \mathrm{~m}$, followed by an emergent trunk model with roots of width $2 \mathrm{~m}$, placed consecutively. The third scenario (model III), which represents a 'compound heterogeneous model' of width $6 \mathrm{~m}$, consists of the submerged seagrass model of width $2 \mathrm{~m}$, followed by a submerged rigid vegetation model of width $2 \mathrm{~m}$ and an emergent trunk model with roots of width $2 \mathrm{~m}$. The simulated vegetation models are placed on the flume bed at about $26-28 \mathrm{~m}$ from the wave generator.

The mechanical and geometric properties of the prototype vegetation were similar to those of Enhalus acoroides and Avicennia officianalis for the seagrass model ${ }^{35}$ and the rigid submerged and emergent trunk model ${ }^{36}$ respectively. The leaves of E. acoroides, a type of seagrass, are long and strap-like and the trunks of $A$. officianalis species are generally of $1 \mathrm{~m}$ diameter ${ }^{37}$, and height 18 $25 \mathrm{~m}$. The Young's modulus of seagrass leaves is approx- imately $0.8 \mathrm{GPa}$ (ref. 38) and that of mangrove trunks ranges from 18 to $20 \mathrm{GPa}$ (ref. 39). A model similarity scale of $1: 30$ was used for the experimental runs to scale down the prototype parameters. The seagrass leaves, and rigid submerged and emergent trunks were constructed using polyethylene sheets and nylon rods with modulus of elasticity values of about 0.6 and $3 \mathrm{GPa}$ respectively. The geometric dimensions of the seagrass leaves, and the trunks and roots were fixed by modelling the stiffness property, EI as a single parameter. Figure 2 shows the simulated model arrangements considered for this experimental study.

Table 1 lists the vegetation characteristics and dimensions of the model. Figure 3 displays the vegetation arrangement pattern of the simulated individual plant models constituting the heterogeneous model.

\section{Test procedure}

The test models designated as submerged heterogeneous model, emergent heterogeneous model and compound heterogeneous types were subjected to varying incident wave heights, wave periods and water depths (Table 1). The relative wave heights $\left(H_{x} / H_{i}\right)$ for the experimental runs were obtained from the recorded observations of incident wave height $\left(H_{i}\right)$ and the corresponding wave heights at different locations within the vegetation model $\left(H_{x}\right)$. For the $4 \mathrm{~m}$ wide submerged and emergent meadows, wave heights were recorded at locations $x=0,1,2$, 3 and $4 \mathrm{~m}$ within the meadow, whereas for the $6 \mathrm{~m}$ wide compound heterogeneous meadow, wave heights at locations $x=0,2,4$ and $6 \mathrm{~m}$ were considered. The wave attenuation, characterized by the percentage wave height reduction at the exit of the meadow was calculated as

$$
\left\{\left[1-\left(\frac{H_{\text {exit }}}{H_{i}}\right)\right] \times 100\right\} .
$$

The influence of wave steepness $\left(H_{i} / g T^{2}\right)$ on percentage wave height reduction is discussed here with emphasis on the effect of relative plant height $\left(h_{s} / d\right)$ and meadow width parameter $(w / L)$, where $T$ is the wave period, 
Table 1. Vegetation characteristics and experimental conditions

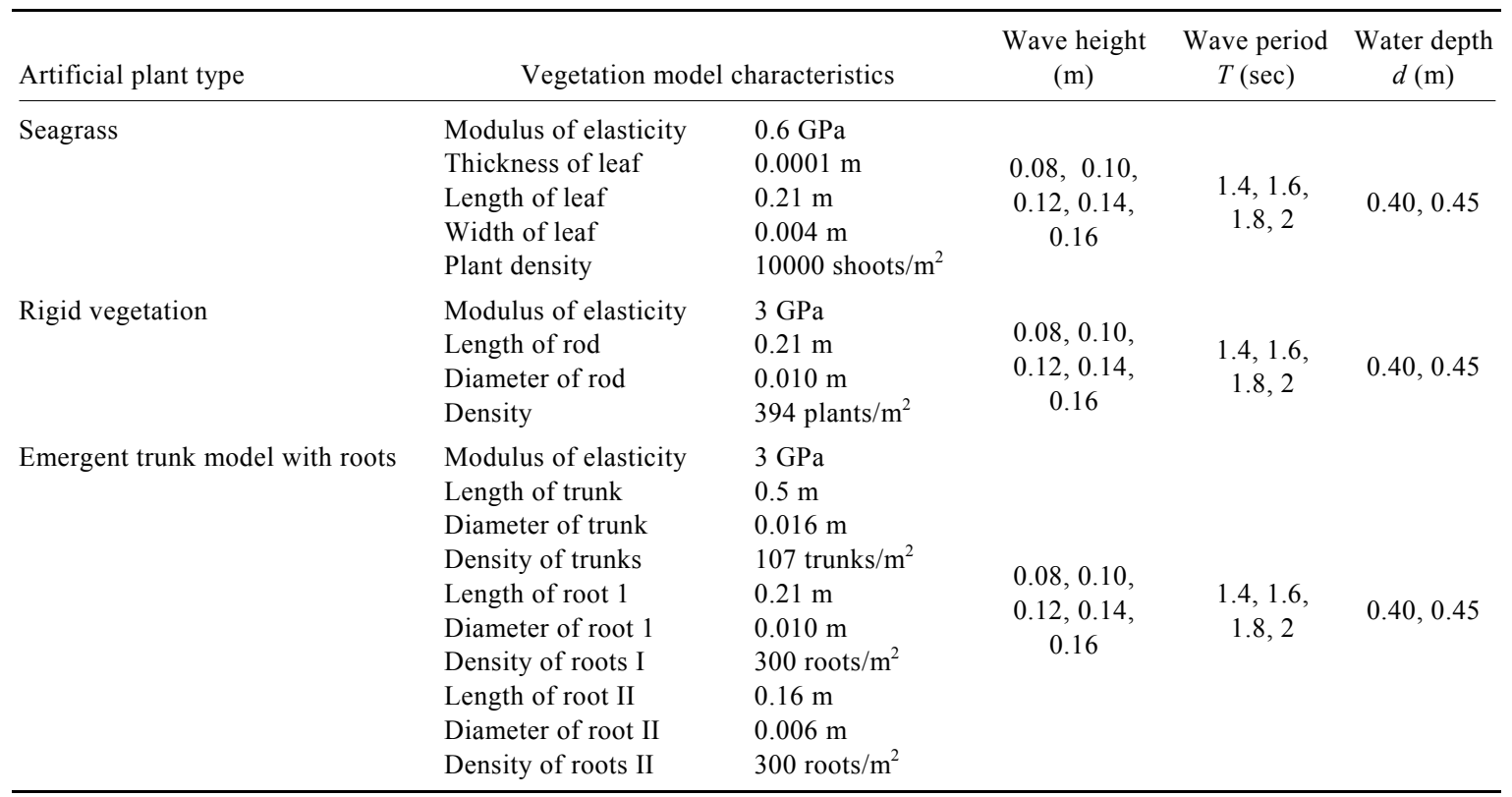
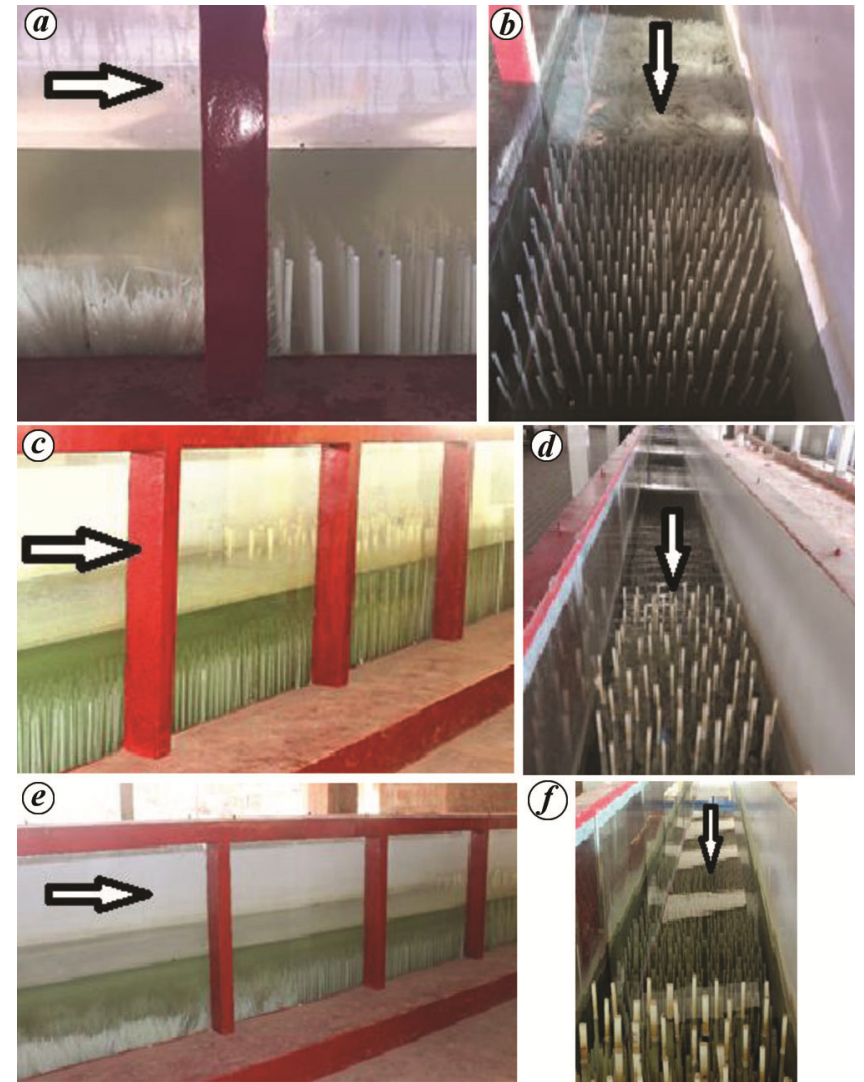

Figure 2. Typical top view and side views of the experimental set-up for $(\boldsymbol{a}, \boldsymbol{b})$ model $1,(\boldsymbol{c}, \boldsymbol{d})$ model II and $(\boldsymbol{e}, \boldsymbol{f})$ model III. (Arrowheads indicate the direction of wave propagation.)

$L$ the wavelength, $d$ the depth of water in the wave flume, $g$ the acceleration due to gravity, $h_{s}$ the length of vegetation and $w$ is the meadow width.

Calibration of the experimental set-up and probe sensitivity was done before the start of the experiment. The calibration of wave flume was carried out by evaluating the relationship between frequency of the inverter and wave period; and eccentricity and wave height for a particular water depth. The output of the probes originally calibrated by the manufacturer is expected to show minor variations due to salinity and temperature conditions. Therefore, the wave probes were subjected to static immersion tests to determine the relationship between water level and output voltage. The models were then subjected to incident waves of height $\left(H_{i}\right)$ ranging from 0.08 to $0.16 \mathrm{~m}$, and wave period $(T)$ ranging from 1.4 to $2 \mathrm{sec}$, in varying water depths $(d)$.

\section{Results and analysis}

The variation of wave heights within the simulated heterogeneous vegetation models was analysed. The measurements of wave height within the model revealed an exponential decay, as proposed by Kobayashi et al. ${ }^{40}$. Vegetation interferes with the particle orbital velocities, resulting in turbulence, energy dissipation and reduction in wave heights ${ }^{36}$.

\section{Submerged heterogeneous model}

Figure 4 depicts the effect of wave steepness parameter $\left(H_{i} / g T^{2}\right)$ on percentage wave height reduction. Wave height reduction from $67.50 \%$ to $60.67 \%$, with an increase of wave steepness parameter, from 0.00416 to 0.00832 $(w / L=1.672, T=1.4 \mathrm{sec})$ was observed. Similar reductions of $67.50 \%$ to $56.88 \%, 63.75 \%$ to $53.75 \%$ and $62.50 \%$ to $51.25 \%$ were observed for wave steepness parameters ranging from 0.00318 to $0.00637(w / L=1.428, T=1.6 \mathrm{sec})$, 


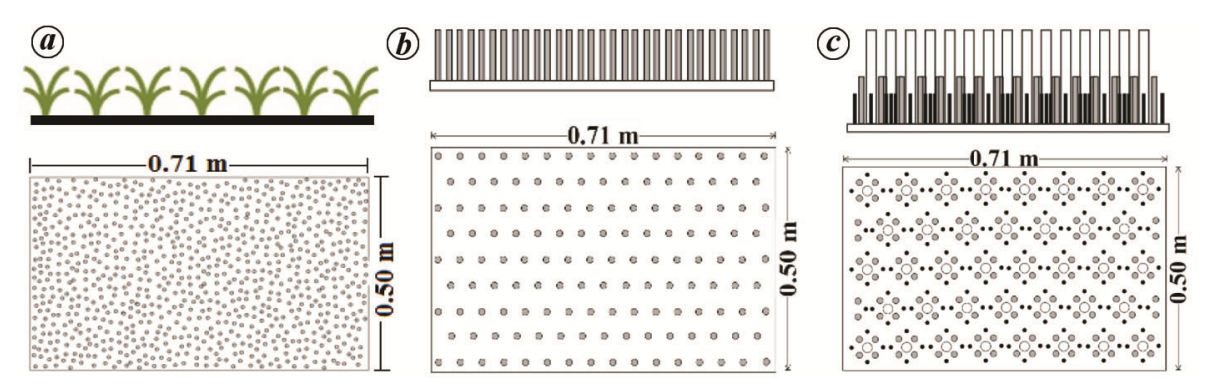

Figure 3. Sketch of vegetation arrangement (side and top views) of (a) seagrass model (b) rigid submerged vegetation model and $(\boldsymbol{c})$ emergent trunk model with roots.
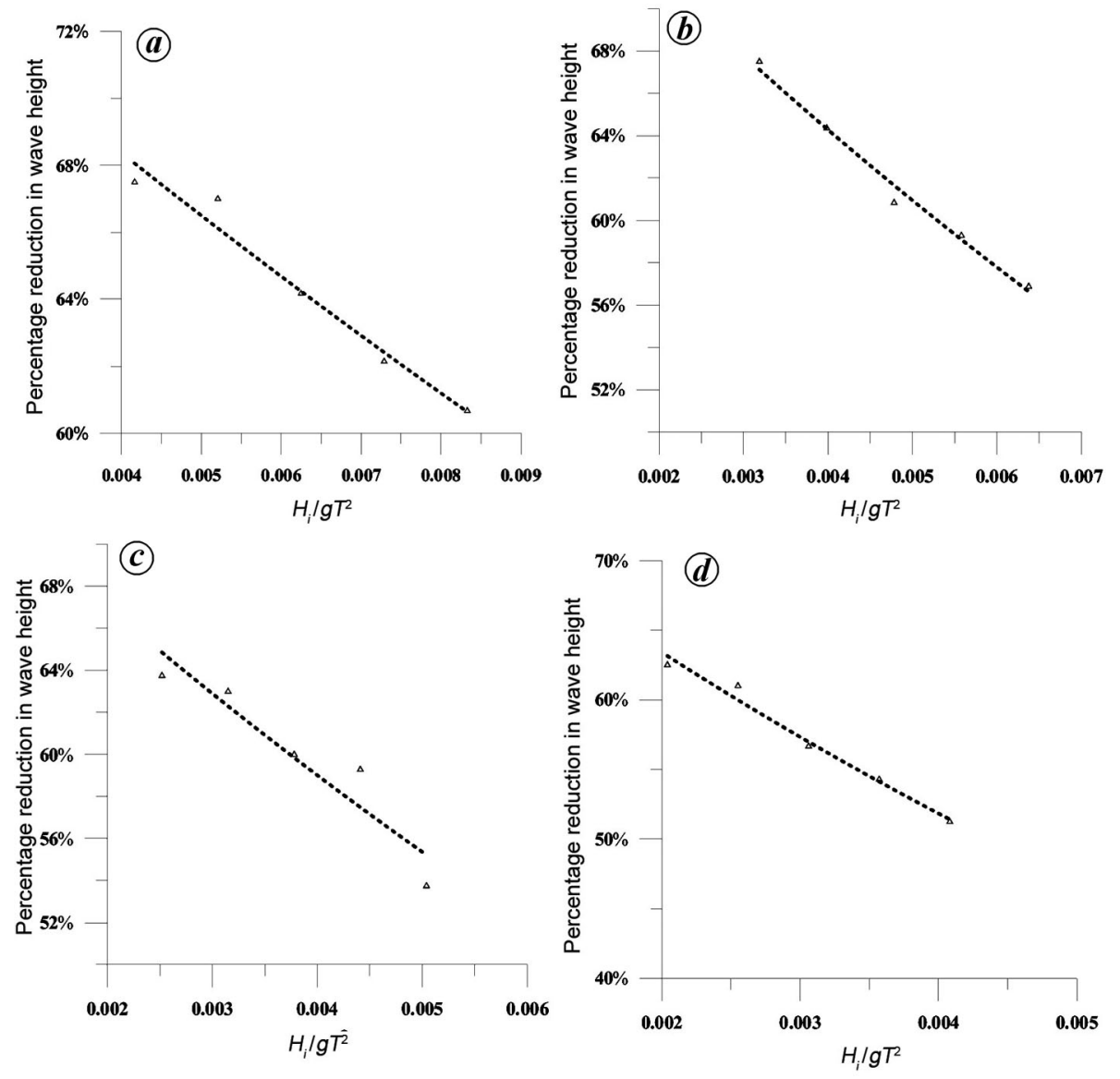

Figure 4. Effect of wave steepness $\left(H_{i} / g T^{2}\right)$ on percentage reduction in wave height for $h_{s} / d=0.525$; $w=4 \mathrm{~m} . \boldsymbol{a}$, For $w / L=1.672, T=1.4 \mathrm{sec} ; \boldsymbol{b}$, For $w / L=1.428, T=1.6 \mathrm{sec} ; \boldsymbol{c}$, For $w / L=1.223, T=1.8 \mathrm{sec}$; $\boldsymbol{d}$, For $w / L=1.082, T=2 \mathrm{sec}$.

0.00251 to $0.00503(w / L=1.223, T=1.8 \mathrm{sec}) \quad$ and 0.00203 to $0.00407(w / L=1.082, T=2 \mathrm{sec})$ respectively.

It is clear from the above results that the heterogenous submerged model exhibits increased wave height reduction when compared to the individual submerged models, namely seagrass and rigid submerged vegetation of width $2 \mathrm{~m} \mathrm{each}^{21,41}$. The wave height reduction for the individual seagrass model was in the range 52.59-42.96\% and $43.96-36.94 \%$ for $h_{s} / d=0.525$ and 0.47 respectively, while for the submerged rigid vegetation model, the reduction was the range $61.50-48.18 \%$ and $55.05-$
$43.17 \%$ for $h_{s} / d=0.525$ and 0.47 respectively. The increased wave height reduction for the heterogenous submerged model is obvious predominantly due to the presence of a seagrass meadow followed by a rigid vegetation bed which aid in increased attenuation. The presence of the initial bed of seagrass of width $2 \mathrm{~m}$ alters the wave orbital velocities, resulting in an increased turbulence, which leads to energy dissipation and wave height reduction. The wave when further propagated along the rigid vegetation meadow undergoes further reduction in wave height due to increased stiffness of stems which 

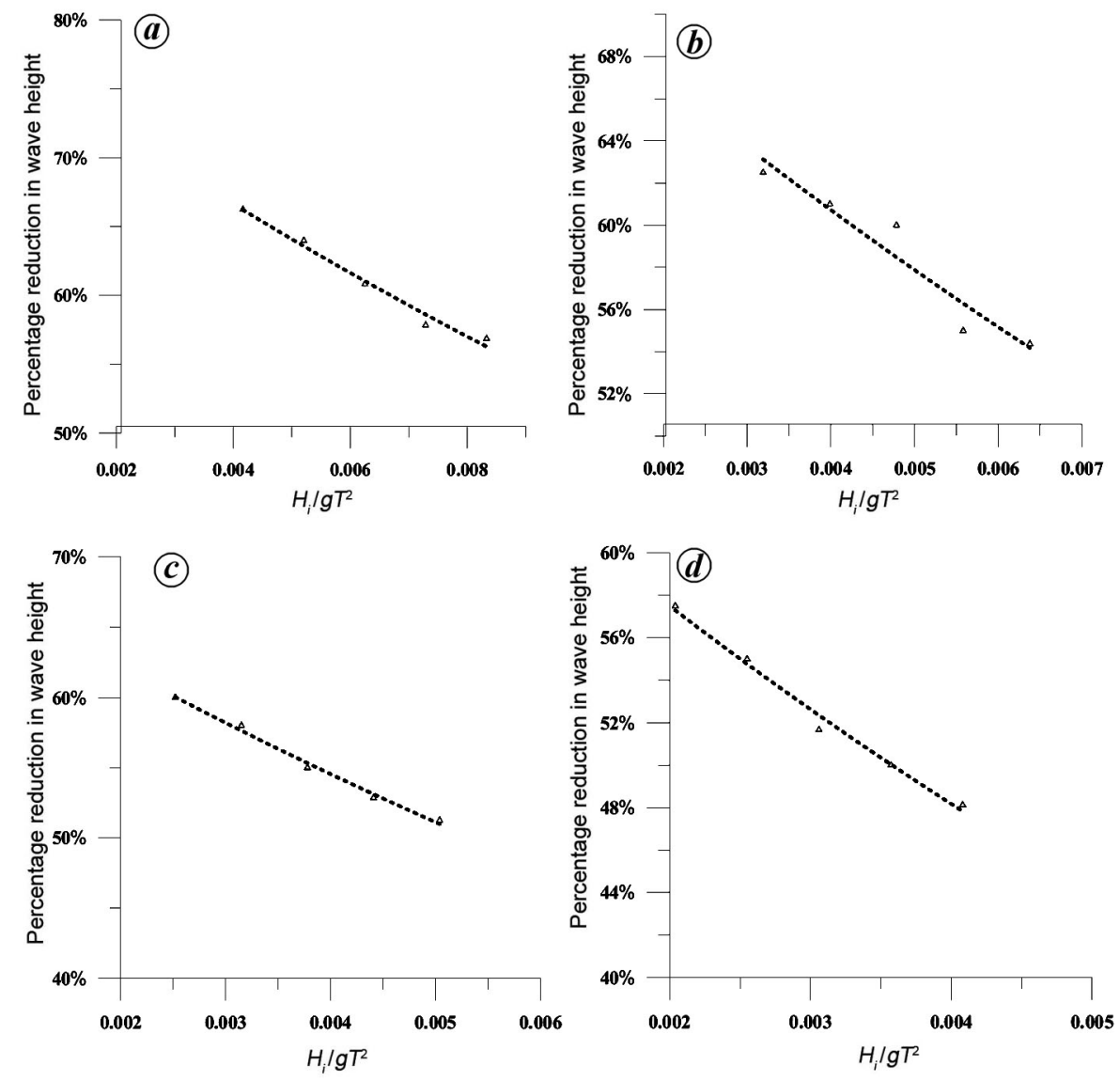

Figure 5. Effect of wave steepness $\left(H_{i} / g T^{2}\right)$ on percentage reduction in wave height for $h_{s} / d=0.47$; $w=4 \mathrm{~m} . \boldsymbol{a}$, For $w / L=1.607, T=1.4 \mathrm{sec} ; \boldsymbol{b}$, For $w / L=1.393, T=1.6 \mathrm{sec} ; \boldsymbol{c}$, For $w / L=1.167, T=1.8 \mathrm{sec}$; d, For $w / L=1.031, T=2 \mathrm{sec}$.

controls the vegetation motion leading to increased wave attenuation.

Figure 5 depicts the wave reduction along a submerged heterogenous vegetation model due to the effect of reduction in relative plant height $\left(h_{s} / d\right)$ from 0.525 to 0.47 , for an increase in water depth from 0.40 to $0.45 \mathrm{~m}$. A variation of reduction in wave height from $66.25 \%$ to $56.88 \%$ for increasing wave steepness ranging from 0.00416 to $0.00832(w / L=1.607, T=1.4 \mathrm{sec})$ was observed (Figure $5 a$ ). Correspondingly, for $w / L=1.393, T=1.6 \mathrm{sec}$, $H_{i} / g T^{2}=0.00318$ to $0.00637 ; w / L=1.167, T=1.8 \mathrm{sec}$, $H_{i} / g T^{2}=0.00251$ to 0.00503 and $w / L=1.031, T=2 \mathrm{sec}$, $H_{i} / g T^{2}=0.00203$ to 0.00407 , the reduction in wave height varied from $62.50 \%$ to $54.38 \%, 60.00 \%$ to $51.25 \%$ and $57.50 \%$ to $48.13 \%$ respectively (Figure $5 b-d$ ).

The results justify the fact that wave height attenuation decreases as $h_{s} / d$ changes from 0.525 to 0.47 . For $h_{s} / d=0.525$, since the depth of water is low, as the wave passes along the width of the heterogeneous model, the leaves/stems successfully interfere with the particle orbital velocities resulting in increased wave attenuation when compared to the case of $h_{s} / d=0.47$. As the degree of interference is less, the wave passes effortlessly which results in reduced wave height attenuation. From the above re- sults, it is clearly noted that there exists an inverse relationship between wave period and wave attenuation.

The wave run-up on the beach, which shows the inundation extent for the submerged heterogeneous model $\left(h_{s} / d=0.525\right.$ ) varied from 0.519 to 0.436 (for $w / L=$ $1.672 ; T=1.4 \mathrm{sec}$ ), 0.550 to 0.450 (for $w / L=1.428$; $T=1.6 \mathrm{sec}$ ), 0.571 to 0.484 (for $w / L=1.223 ; T=1.8 \mathrm{sec}$ ) and 0.737 to 0.576 (for $w / L=1.082 ; T=2 \mathrm{sec}$ ), whereas it varied from 0.571 to 0.457 (for $w / L=1.607 ; T=$ $1.4 \mathrm{sec}$ ), 0.592 to 0.472 (for $w / L=1.393 ; T=1.6 \mathrm{sec}$ ), 0.623 to 0.488 (for $w / L=1.167 ; T=1.8 \mathrm{sec}$ ) and 0.764 to 0.612 (for $w / L=1.031 ; T=2 \mathrm{sec}$ ), as the water depth increased to $0.45 \mathrm{~m}\left(h_{s} / d=0.47\right)$.

The reduction in wave height for the submerged heterogeneous model of width $4 \mathrm{~m}$, for $h_{s} / d=0.525$, ranged from $67.50 \%$ to $51.25 \%$ for the entire set of incident wave parameters. The corresponding wave run-up measurements $\left(R_{u} / H_{i}\right)$ on the beach slope ranged from 0.737 to 0.436 , for an increase in wave steepness parameter from 0.00203 to 0.00833 (Figure $6 a$ ). Therefore, the relative wave run-up decreased with an increase in wave steepness parameter, whereas it varied from 0.764 to 0.457 for $h_{s} / d=0.47$ (Figure $6 b$ ), corresponding to wave height reduction ranging from $66.25 \%$ to $48.13 \%$. These 

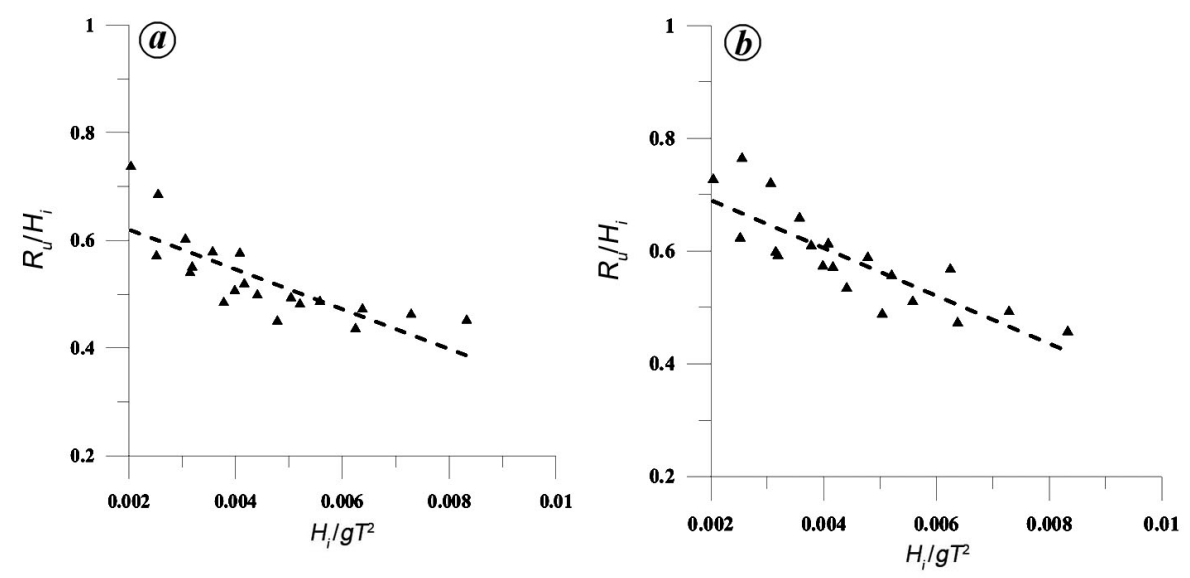

Figure 6. Effect of wave steepness on wave run-up for varying relative plant height $\left(h_{s} / d\right)$. $\boldsymbol{a}$, For $h_{s} / d=0.525 ; \boldsymbol{b}$, For $h_{s} / d=0.47$.
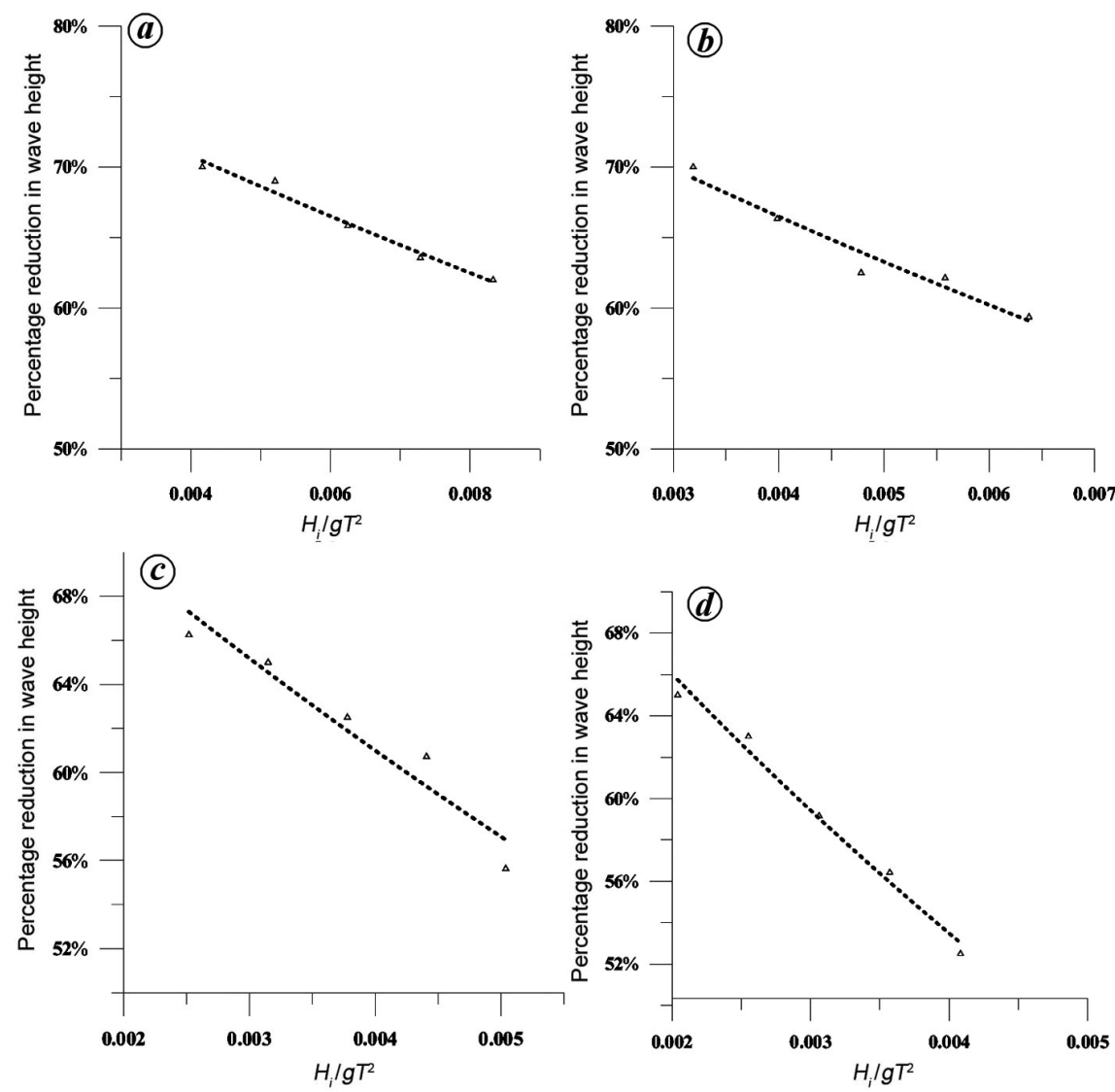

Figure 7. Effect of wave steepness $\left(H_{i} / g T^{2}\right)$ on percentage reduction in wave height for $h_{s} / d=1.25$ $w=4 \mathrm{~m} . \boldsymbol{a}$, For $w / L=1.672, T=1.4 \mathrm{sec} ; \boldsymbol{b}$, For $w / L=1.428, T=1.6 \mathrm{sec} ; \boldsymbol{c}$, For $w / L=1.223, T=1.8 \mathrm{sec}$ $\boldsymbol{d}$, For $w / L=1.082, T=2 \mathrm{sec}$.

results show that the extent of inundation on the beach depends on the extent of attenuation of wave height.

\section{Emergent heterogeneous model}

Experimental studies on wave attenuation due to emergent vegetation models revealed that the presence of vegetation patches near the surface aids in the dissipation of wave energy further, as it increasingly interferes with the wave field propagating above and offers more frictional resistance ${ }^{36}$.

The presence of trunks and roots in the emergent vegetation model along with the submerged rigid vegetation model leads to an increased attenuation of wave height because of the increased plant density and plant height. 

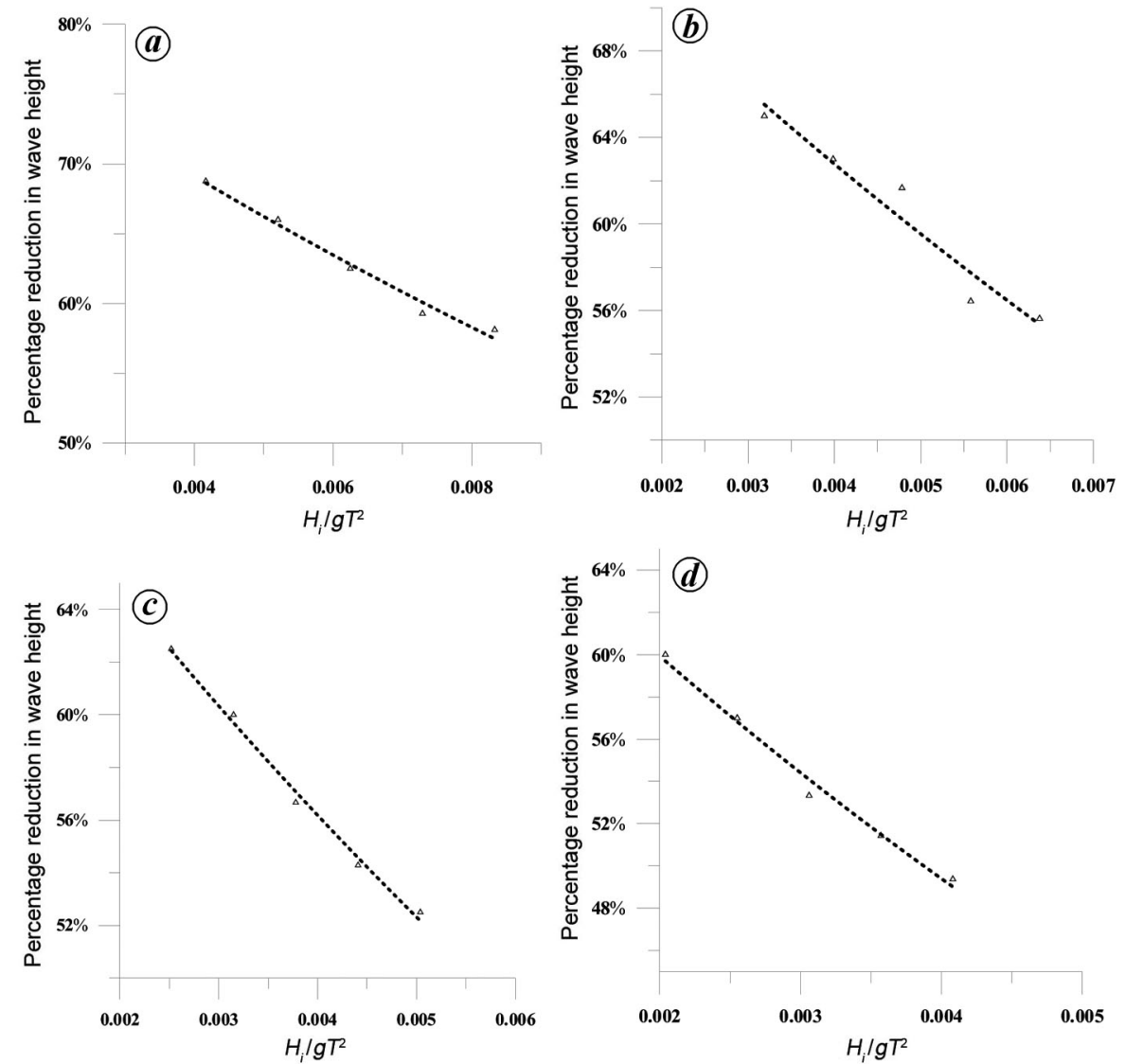

Figure 8. Effect of wave steepness $\left(H_{i} / g T^{2}\right)$ on percentage reduction in wave height for $h_{s} / d=1.11$; $w=4 \mathrm{~m} . \boldsymbol{a}$, For $w / L=1.607, T=1.4 \mathrm{sec} ; \boldsymbol{b}$, For $w / L=1.393, T=1.6 \mathrm{sec} ; \boldsymbol{c}$, For $w / L=1.167, T=1.8 \mathrm{sec}$ $\boldsymbol{d}$, For $w / L=1.031, T=2 \mathrm{sec}$.

The reduction in wave height for an emergent heterogeneous model $70.00 \%$ to $52.50 \%$ when compared to a reduction of $67.50 \%$ to $51.25 \%$ for the case of the submerged heterogeneous model of the same meadow width parameter $(w / L=1.672-1.082)$, for $h_{s} / d=1.25$ and 0.525 respectively. The above results confirm that the wave height reduction is higher for the emergent heterogeneous model, since the emergence of trunks provides increased interference in the wave field. As the wave propagates along the submerged heterogeneous model, there is reduction in wave height, but as it passes through the emergent heterogeneous model, the increased turbulence due to emergence of the trunk along with the roots leads to further wave height reduction.

Figure $7 a-d$ illustrates that as $H_{i} / g T^{2}$ increases from 0.00416 to $0.00832,0.00318$ to $0.00637,0.00251$ to 0.00503 and from 0.00203 to 0.00407 , the reduction in wave height varies from $70.00 \%$ to $62.00 \%, 70.00 \%$ to $59.38 \%, 66.25 \%$ to $55.63 \%$ and $65.00 \%$ to $52.50 \%$ respectively.

Figure $8 a-d$ illustrates the relative wave heights at different positions along the emergent heterogeneous model of width $4 \mathrm{~m}$, for $h_{s} / d=1.11$ subjected to waves of varying heights and periods.
For $w / L=1.607, T=1.4 \mathrm{sec}$, as the wave steepness parameter increased from 0.00416 to 0.00832 , a reduction in wave heights ranging from $68.75 \%$ to $58.13 \%$, was observed (Figure $8 a$ ). A similar decrease in wave height from $65.00 \%$ to $55.63 \%, 62.50 \%$ to $52.50 \%$ and $60.00 \%$ to $49.38 \%$ was observed for the cases corresponding to $w / L=1.393, T=1.6 \mathrm{sec} ; w / L=1.167, T=1.8 \mathrm{sec}$ and $w / L=1.031, T=2 \mathrm{sec}$ respectively (Figure $8 b-d$ ).

Figure $9 a-b$ shows the effect on wave run-up over the beach slope, with an increase in $H_{i} / g T^{2}$ for the emergent heterogeneous model of width $4 \mathrm{~m}$, corresponding to relative plant height, $h_{s} / d=1.25$ and 1.11 and wave period $T=1.4-2 \mathrm{sec}$.

As the wave steepness parameter increased from 0.00203 to $0.00832, R_{u} / H_{i}$ decreased from 0.706 to 0.403 for the case of emergent heterogeneous model of width $4 \mathrm{~m}\left(h_{s} / d=1.25\right)$, whereas it varied from 0.716 to 0.400 for the same model for $h_{s} / d=1.11$, subjected to incident wave heights ranging from $0.08 \mathrm{~m}$ to $0.16 \mathrm{~m}$ and period $T$ from 1.4 to $2 \mathrm{sec}$ (Figure 9). These results when compared with the percentage reduction in wave height strongly suggests that as the percentage reduction in wave height increases, there is a decreased extent of inundation on the beach slope. The increased reduction of wave 

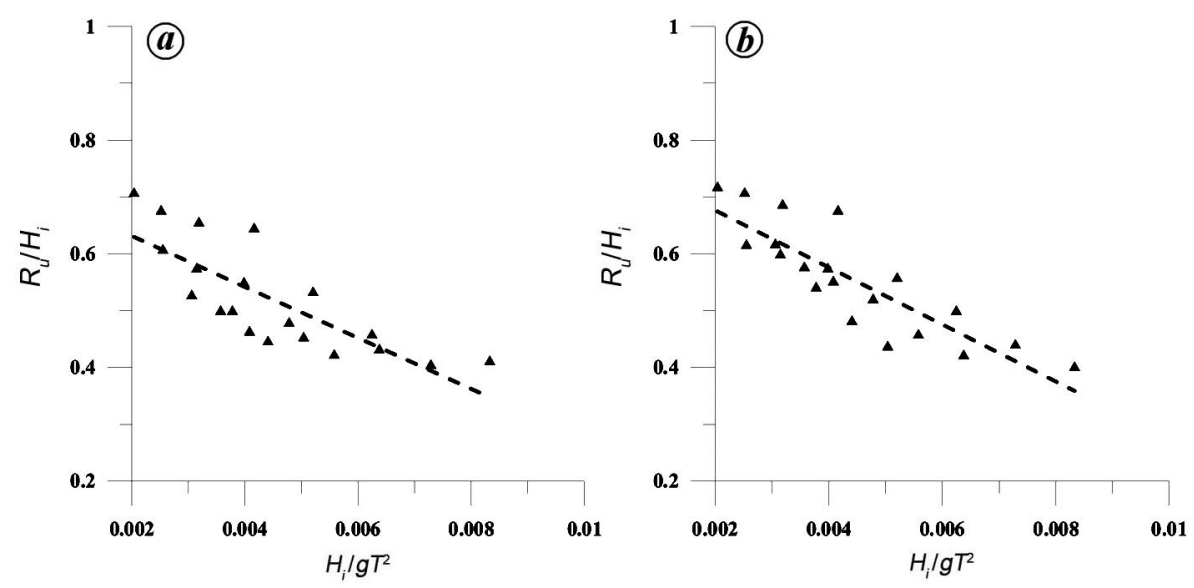

Figure 9. Effect of wave steepness on wave run-up for varying relative plant height $\left(h_{s} / d\right) . \boldsymbol{a}$, For $h_{s} / d=1.25 ; \boldsymbol{b}$, For $h_{s} / d=1.11$.
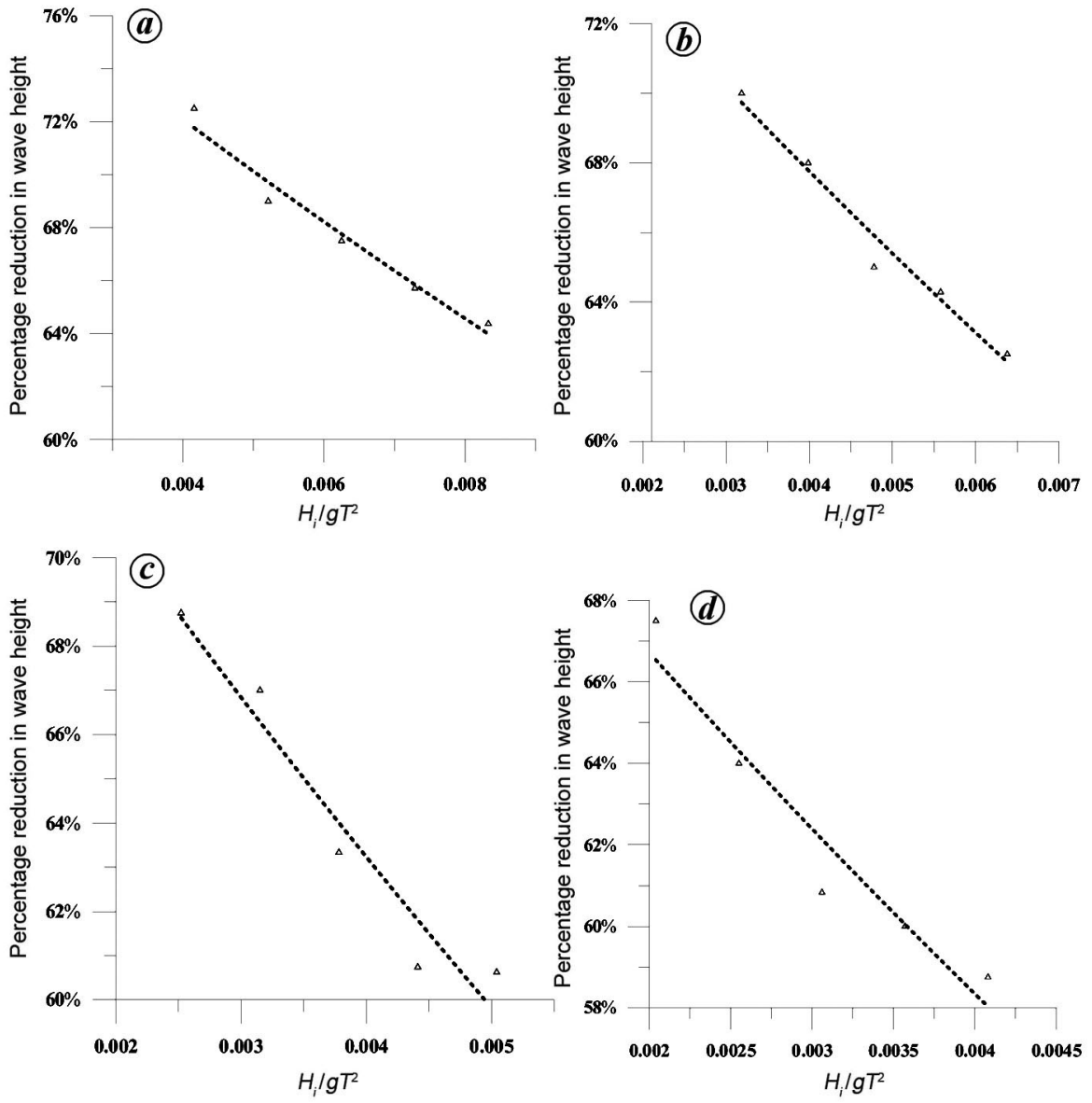

Figure 10. Effect of wave steepness $\left(H_{i} / g T^{2}\right)$ on percentage reduction in wave height for $h_{s} / d=1.25$; $w=6 \mathrm{~m}$. $\boldsymbol{a}$, For $w / L=2.508, T=1.4 \mathrm{sec} ; \boldsymbol{b}$, For $w / L=2.142, T=1.6 \mathrm{sec} ; \boldsymbol{c}$, For $w / L=1.835, T=1.8 \mathrm{sec}$; $\boldsymbol{d}$, For $w / L=1.623, T=2 \mathrm{sec}$.

run-up over the beach slope for the emergent heterogeneous model when compared to the submerged heterogeneous model can be attributed to the presence of emergent trunks and roots in this model which causes increased wave height attenuation and subsequent reduction in wave run-up.

\section{Compound heterogeneous model}

Previous studies conducted in this area have shown that the width of the meadow, height of emergence of vegetation and plant density play a pivotal role in attenuating the waves passing through the meadow ${ }^{21,36}$. The compound 

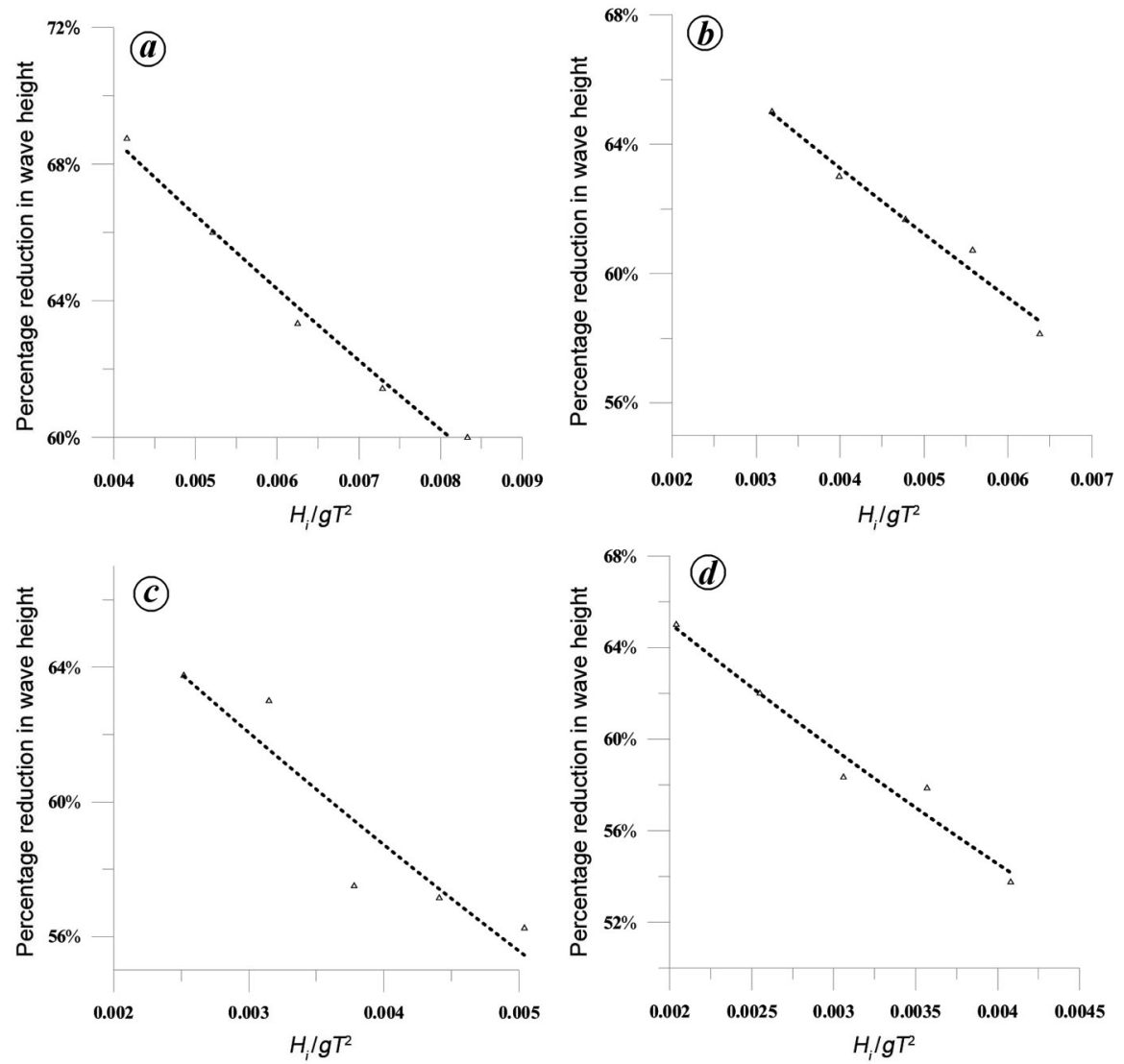

Figure 11. Effect of wave steepness $\left(H_{i} / g T^{2}\right)$ on percentage reduction in wave height for $h_{s} / d=1.11$ $w=6 \mathrm{~m} . \boldsymbol{a}$, For $w / L=2.411, T=1.4 \mathrm{sec} ; \boldsymbol{b}$, For $w / L=2.089, T=1.6 \mathrm{sec} ; \boldsymbol{c}$, For $w / L=1.750, T=1.8 \mathrm{sec}$; d, For $w / L=1.546, T=2 \mathrm{sec}$.

heterogeneous model which is subjected to the test runs consists of both submerged as well as emergent models. Therefore, this model satisfies increase in width of the meadow $(6 \mathrm{~m})$, variation in vegetation height and plant density.

In this complex model consisting of three types of simulated vegetation, as the wave passes through the seagrass meadow, the wave height decreases due to interference of the seagrass leaves with the wave field. As the wave further propagates along the rigid submerged model and the emergent model, the wave height further decreases owing to the increased resistance provided by the submerged stems and increased turbulence due to the emergent trunks.

Figure $10 a-d$ exhibits the effect of wave steepness parameter on percentage wave height reduction for this model. A variation of wave height reduction from $70.00 \%$ to $64.38 \%$ for $T=1.4 \mathrm{sec}, w / L=2.508$ and $H_{i} / g T^{2}=$ 0.00416 to 0.00832 was observed (Figure $10 a$ ). Variation in reduction in wave height from $70.00 \%$ to $62.50 \%$, $68.75 \%$ to $60.63 \%$ and $67.50 \%$ to $58.75 \%$ was observed for the compound heterogeneous model with $w / L=2.142$, $T=1.6 \mathrm{sec}, H_{i} / g T^{2}$ from 0.00318 to $0.00637 ; w / L=$ $1.835, T=1.8 \mathrm{sec}, H_{i} / g T^{2}$ from 0.00251 to 0.00503 , and $w / L=1.623, T=2 \mathrm{sec}, H_{i} / g T^{2}$ from 0.00203 to 0.00407 respectively (Figure $10 a-d$ ).

As the relative plant height $\left(h_{s} / d\right)$ decreased from 1.25 to 1.11 due to increase in water depth from $0.40 \mathrm{~m}$ to $0.45 \mathrm{~m}$, the reduction in wave height for increasing wave steepness, varied from $68.75 \%$ to $60.00 \%$ for $H_{i} / g T^{2}$ ranging from 0.00416 to $0.00832(w / L=2.411, T=1.4 \mathrm{sec})$ (Figure $11 a$ ). Correspondingly, for $w / L=2.089, T=$ $1.6 \mathrm{sec}, H_{i} / g T^{2}=0.00318$ to $0.00637 ; w / L=1.750, T=$ $1.8 \mathrm{sec}, H_{i} / g T^{2}=0.00251$ to 0.00503 , and $w / L=1.546$, $T=2 \mathrm{sec}, H_{i} / g T^{2}=0.00203$ to 0.00407 , the reduction in wave height varied from $65.00 \%$ to $58.13 \%, 63.75 \%$ to $56.25 \%$ and $65.00 \%$ to $53.75 \%$ respectively (Figure $11 b$ d). The above results justify the fact that wave height attenuation decreases as $h_{s} / d$ changes from 1.25 to 1.11 . For $h_{s} / d=1.25$, the trunks of the model successfully interfere with the waves due to decreased water depth condition, which results in increased wave attenuation when compared to the case of $h_{s} / d=1.11$. As the degree of interference is less, owing to decreased relative plant height, the wave passes effortlessly which results in reduced wave attenuation. From the above results, it is clear that there exists an inverse relationship between wave period and wave attenuation. 

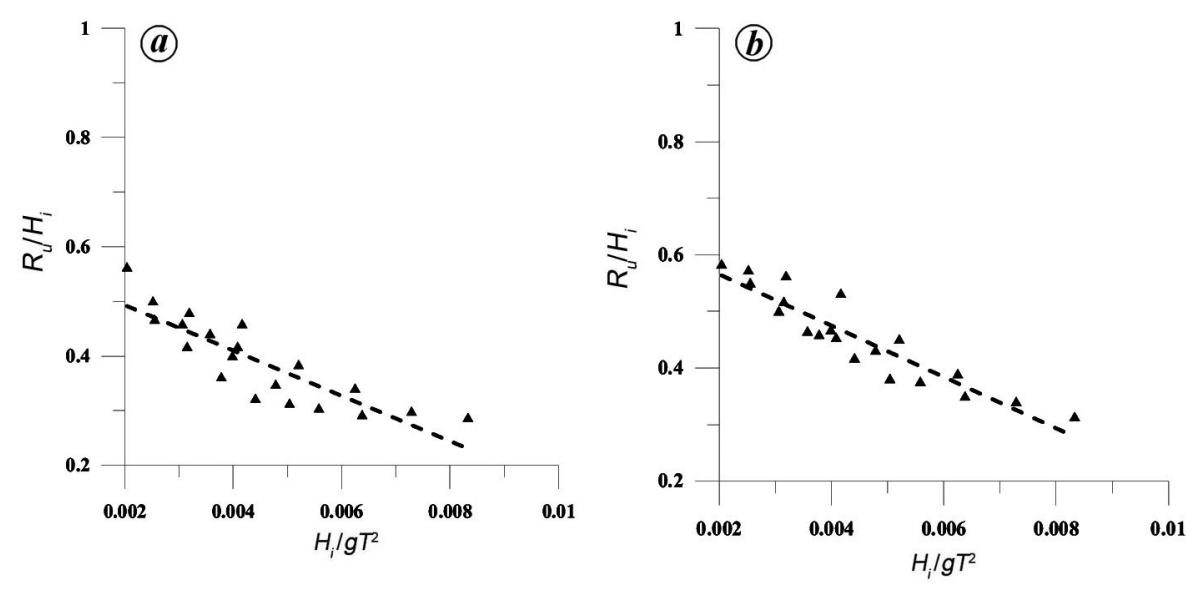

Figure 12. Effect of wave steepness on wave run-up for varying relative plant height $\left(h_{s} / d\right)$. $\boldsymbol{a}$, For $h_{s} / d=1.25 ; \boldsymbol{b}$, For $h_{s} / d=1.11$.

Figure $12 a$ and $b$ shows the variation of wave run-up over the beach slope with an increase in wave steepness for the compound heterogeneous model of width $6 \mathrm{~m}$, corresponding to relative plant heights $h_{s} / d=1.25$ and 1.11 and wave period $T=1.4-2$ sec.

As $H_{i} / g T^{2}$ increased from 0.00203 to $0.00832, R_{u} / H_{i}$ decreased from 0.561 to 0.285 for the case of compound heterogeneous model of width $6 \mathrm{~m}\left(h_{s} / d=1.25\right)$, wherein the reduction in wave height varied from $72.50 \%$ to $58.75 \%$. However, the relative wave run-up on the beach varied from 0.581 to 0.311 for the same model for relative plant height $h_{s} / d=1.11$, subjected to incident wave heights ranging from $0.08 \mathrm{~m}$ to $0.16 \mathrm{~m}$ and period $T=1.4-2 \mathrm{sec}$ (Figure $12 \mathrm{~b}$ ); for which the reduction in wave height varied from $68.75 \%$ to $53.75 \%$.

\section{Concluding remarks}

The results of the present study highlight the role of wave characteristics and vegetation characteristics in dissipating wave energy and thus inundation on the beach. A comparison of the results reveals that the compound heterogeneous model of width $6 \mathrm{~m}$ displays increased wave attenuation and the corresponding extent of inundation on the beach. The submerged heterogeneous model shows less reduction in wave heights when compared to the emergent heterogeneous model. The stiffness of the stem as well as the trunk of the emergent heterogeneous model have a greater impact on the wave attenuation pattern, whereas the swaying and bending motion of the seagrass meadow in the model alters the hydrodynamics of the wave action to a lesser extent when compared to the emergent heterogeneous model. The height of emergence of the emergent heterogeneous model plays a crucial role in attenuating the waves. The emergent trunk along with the roots can provide increased interference in the wave field by altering the particle orbital velocities along the water depth considered. The percentage reduction in wave heights is highest for the compound heterogeneous model which is characterized by the presence of all three types of vegetation, viz. submerged seagrass, rigid vegetation and the emergent trunk model with roots.

The results of the compound heterogeneous model show maximum reduction in wave height $(72.50 \%$ to $58.75 \%$ for $h_{s} / d=1.25$ ), mainly characterized by the increase in meadow width parameter as well as height of emergence of the trunk, which leads to effective penetration of the layers of varying particle orbital velocities. A comparison between the results presented in this study and those of a field study on the capability of coral reefs, seagrasses and mangroves in protecting coastal regions by Guannel et al. ${ }^{31}$, wherein mangroves are capable of systematically reducing wave heights by more than $70 \%$, reveals comparable wave attenuation for heterogeneous vegetation models. The results of this study indicate that live corals and seagrasses together provide more protection benefits than either of these habitats alone ${ }^{31}$.

The findings from this physical model study reveal that the compound heterogeneous model consisting of seagrass meadow, rigid submerged model and the emergent model shows maximum reduction in wave height and subsequent reduction in beach inundation. However, facilitation of interaction between the three prototype species depends upon many other ecological factors, including flow of energy, materials and organisms ${ }^{42}$, which have not been considered in this study which focuses only on the effect of heterogeneous plant communities on wave attenuation as well as its influence on beach inundation. This small-scale experimental study confirms the fact that marine ecosystems that coexist as heterogenous seascapes are effective in reducing wave height as well as controlling coastal flooding.

1. McCarthy, J. J., Canziani, O. F., Leary, N. A., Dokken, D. J. and White, K. S., Climate change 2001: impacts, adaptation, and vulnerability: contribution of Working Group II to the third 
assessment report of the Intergovernmental Panel on Climate Change (vol. 2), Cambridge University Press, 2001

2. Rahman, S. and Rahman, M. A., Climate extremes and challenges to infrastructure development in coastal cities in Bangladesh. Weather Climate Extremes, 2015, 7, 96-108.

3. Viles, H. and Spencer, T., Coastal Problems: Geomorphology, Ecology and Society at the Coast, Routledge, 2014.

4. Baas, A. C. and Nield, J. M., Modelling vegetated dune landscapes. Geophys. Res. Lett., 2007, 34(6), L06405.

5. Fonseca, M. S., Sediment stabilization by Halophila decipiens in comparison to other seagrasses. Estuarine, Coastal Shelf Sci., 1989, 29(5), 501-507.

6. Gacia, E., Duarte, C. M., Marba, N., Terrados, J., Kennedy, H., Fortes, M. D. and Tri, N. H., Sediment deposition and production in SE-Asia seagrass meadows. Estuarine, Coastal Shelf Sci., 2003, 56(5), 909-919.

7. Kathiresan, K., How do mangrove forests induce sedimentation? Rev. Biol. Trop., 2003, 51(2), 355-360.

8. Furukawa, K. and Wolanski, E., Sedimentation in mangrove forests. Mangroves Salt Marshes, 1996, 1(1), 3-10.

9. Bird, E. C., Coastal Geomorphology: An Introduction, John Wiley, 2011.

10. Kathiresan, K. and Rajendran, N., Coastal mangrove forests mitigated tsunami. Estuarine Coastal Shelf Sci., 2005, 65(3), 601-606.

11. Duarte, C. M., Losada, I. J., Hendriks, I. E., Mazarrasa, I. and Marbà, N., The role of coastal plant communities for climate change mitigation and adaptation. Nature Climate Change, 2013, 3(11), 961-968.

12. Jackson, G. A., Internal wave attenuation by coastal kelp stands. J. Phys. Oceanogr., 1984, 14(8), 1300-1306.

13. Dalrymple, R. A., Kirby, J. T. and Hwang, P. A., Wave diffraction due to areas of energy dissipation. J. Waterway Port Coastal Ocean Eng., 1984, 110(1), 67-79.

14. Dubi, A. and Torum, A., Wave damping by kelp vegetation. Coastal Eng., 1994, 142-156.

15. Lovas, S. M. and Torum, A., Effect of the kelp Laminaria hyperborea upon sand dune erosion and water particle velocities. Coastal Eng., 2001, 44, 37-63.

16. Fonseca, M. S. and Cahalan, J. A., A preliminary evaluation of wave attenuation by four species of seagrass. Estuarine Coastal Shelf Sci., 1992, 35(6), 565-576.

17. Mendez, F. J. and Losada, I. J., An empirical model to estimate the propagation of random breaking and nonbreaking waves over vegetation fields. Coastal Eng., 2004, 51, 103-118.

18. Sánchez-González, J. F., Sánchez-Rojas, V. and Memos, C. D., Wave attenuation due to Posidonia oceanica meadows. J. Hydraul. Res., 2011, 49, 503-514.

19. Koftis, T., Prinos, P. and Stratigaki, V., Wave damping over artificial Posidonia oceanica meadow: a large-scale experimental study. Coastal Eng., 2012, 73, 71-83.

20. Zeller, R. B., Weitzman, J. S., Abbett, M. E., Zarama, F. J., Fringer, O. B. and Koseff, J. R., Improved parameterization of seagrass blade dynamics and wave attenuation based on numerical and laboratory experiments. Limnol. Oceanogr., 2014, 59(1), 251-266.

21. John, B. M., Shirlal, K. G., Rao, S. and Rajasekaran, C., Effect of artificial seagrass on wave attenuation and wave run-up. Int. J. Ocean Climate Syst., 2016, 7(1), 14-19.

22. Bouma, T. J., De Vries, M. B., Low, E., Peralta, G., Tánczos, I. V., van de Koppel, J. and Herman, P. J., Trade-offs related to ecosystem engineering: a case study on stiffness of emerging macrophytes. Ecology, 2005, 86(8), 2187-2199.

23. Möller, I., Quantifying saltmarsh vegetation and its effect on wave height dissipation: results from a UK east coast saltmarsh. Estuarine Coastal Shelf Sci., 2006, 69(3), 337-351.
24. Struve, J., Falconer, R. A. and $\mathrm{Wu}, \mathrm{Y}$., Influence of model mangrove trees on the hydrodynamics in a flume. Estuarine Coastal Shelf Sci., 2003, 58, 163-171.

25. Vo-Luong, P. and Massel, S., Energy dissipation in non-uniform mangrove forests of arbitrary depth. J. Mar. Syst., 2008, 74(1), 603-622.

26. Bao, T. Q., Effect of mangrove forest structures on wave attenuation in coastal Vietnam. Oceanologia, 2011, 53(3), 807-818.

27. Husrin, S., Strusińska, A. and Oumeraci, H., Experimental study on tsunami attenuation by mangrove forest. Earth, Planets Space, 2012, 64(10), 973-989.

28. Horstman, E., Dohmen-Janssen, M., Narra, P., van den Berg, N. J., Siemerink, M., Balke, T. and Hulscher, S., Wave attenuation in mangrove forests; field data obtained in Trang, Thailand. Coastal Eng. Proc., 2012, 1(33), 40.

29. Ozeren, Y., Wren, D. G. and Wu, W., Experimental investigation of wave attenuation through model and live vegetation. J. Waterway Port Coastal Ocean Eng., 2013, 140(5), 04014019.

30. National Institute for Environmental Studies, Tropical Coastal Ecosystems Portal, 2015; http://www.nies.go.jp/TroCEP/index.html

31. Guannel, G., Arkema, K., Ruggiero, P. and Verutes, G., The power of three: coral reefs, seagrasses and mangroves protect coastal regions and increase their resilience. PLOS ONE, 2016, 11(7), e0158094.

32. Grober-Dunsmore, R., Pittman, S. J., Caldow, C., Kendall, M. S. and Frazer, T. K., A landscape ecology approach for the study of ecological connectivity across tropical marine seascapes. In Ecological Connectivity Among Tropical Coastal Ecosystems, Springer, The Netherlands, 2009, pp. 493-530.

33. Barbier, E. B. and Lee, K. D., Economics of the marine seascape. Int. Rev. Environ. Resour. Econ., 2014, 7(1), 35-65.

34. Isaacson, M., Measurement of regular wave reflection. J. Waterways, Port Coastal Ocean Eng., ASCE, 1991, 117, 553-569.

35. John, B. M., Babu, M., Shirlal, K. G. and Rao, S., Experimental investigations of wave height attenuation by submerged artificial vegetation. In Hydrologic Modelling, Water Science and Technology Library, Springer, 2018, pp. 499-509; ISBN: 978-981-105800-4.

36. John, B. M., Shirlal, K. G. and Rao, S., Laboratory investigations of wave attenuation by simulated vegetation of varying densities. ISH J. Hydraul. Eng. (Spec. Issue), 2019, 25(2), 203-213.

37. Little Jr, E. L., Common fuelwood crops. A Handbook for their Identification, Communi Tech Associates, USA, 1983.

38. Folkard, A. M., Hydrodynamics of model Posidonia oceanica patches in shallow water. Limnol. Oceanogr., 2005, 50(5), 15921600 .

39. Gan, K. S., Lim, S. C., Choo, K. T. and Jantan, M. D., Timber notes-medium hardwoods 4. In Timber Technology Bulletin 21, 2001, pp. 1-7.

40. Kobayashi, N., Raichle, A. W. and Asano, T., Wave attenuation by vegetation. J. Waterway Port, Coastal Ocean Eng., 1993, 119, 30-48.

41. John, B. M., Shirlal, K. G. and Rao, S., Effect of artificial vegetation on wave attenuation - an experimental investigation. Proc. Eng., 2015, 116, 600-606.

42. Bruno, J. F., Stachowicz, J. J. and Bertness, M. D., Inclusion of facilitation into ecological theory. Trends Ecol. Evol., 2003, 18(3), $119-125$.

Received 25 April 2019; revised accepted 29 July 2020

doi: $10.18520 / \mathrm{cs} / \mathrm{v} 119 / \mathrm{i} 8 / 1322-1332$ 